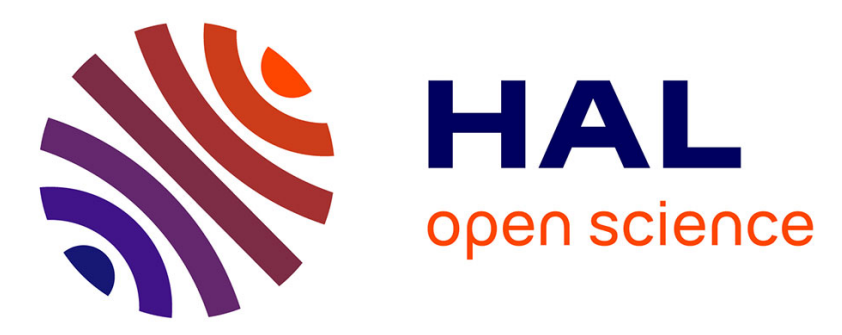

\title{
Wood excavation, construction, and architecture in two Reticulitermes subterranean termites
}

\author{
L. Berville, E. Darrouzet
}

\section{To cite this version:}

L. Berville, E. Darrouzet. Wood excavation, construction, and architecture in two Reticulitermes subterranean termites. Insectes Sociaux, 2019, 66 (3), pp.403 - 411. 10.1007/s00040-019-00696-x . hal-02794520

HAL Id: hal-02794520

https://hal-univ-tours.archives-ouvertes.fr/hal-02794520

Submitted on 19 Jun 2020

HAL is a multi-disciplinary open access archive for the deposit and dissemination of scientific research documents, whether they are published or not. The documents may come from teaching and research institutions in France or abroad, or from public or private research centers.
L'archive ouverte pluridisciplinaire HAL, est destinée au dépôt et à la diffusion de documents scientifiques de niveau recherche, publiés ou non, émanant des établissements d'enseignement et de recherche français ou étrangers, des laboratoires publics ou privés. 
Click heręto view linked References

2

\title{
Laurence Berville, Eric Darrouzet*
}

IRBI, UMR CNRS 7261, University of Tours, Parc de Grandmont, 37200 Tours, France

*Corresponding author: eric.darrouzet@univ-tours.fr

\begin{abstract}
:
Collective constructions are marvels of complexity, composed of networks of tunnels and chambers. However, it is difficult to study subterranean nests without using invasive techniques because the nests are built within pieces of wood and/or in the soil. Using computerized tomography scans and medical imaging software (OsiriX), we were able to observe nest creation, constructions, and architecture of two subterranean termite species. We monitor the nests' growth in three dimensions built by two Reticulitermes species: $R$. grassei, a species native to Europe, and R. flavipes, an invasive species introduced from North America, over a severalmonth period. Doing so, we wanted to know whether the construction of the nest could participate to the invasive success of $R$. flavipes. Although the two species displayed some similarities (i.e., nest creation, chamber size, and levels of wood consumption), only $R$. flavipes built interior structures. Some of these structures changed over time and thus might play a role in the trade-off between wood consumption, colony protection, and environmental homeostasis.
\end{abstract}

\section{Significance Statement}

Nest architectures and their management is one of the triumphs of social animals such as social insects. The functional analysis of those structures composed of networks of tunnels and chambers could help to understand the biology and ecology of their builders. Excavation, consumption and nest design are important parameters in explaining a number of interesting biological traits such as the establishment of invasive species. Some recent studies have introduced X-ray tomography as a tool to analyze insect architectures. We employed this noninvasive technique to observe nest creations, construction and evolution in time, and resolve three-dimensional nest architecture. We analyzed a native and an invasive subterranean termite species. Interestingly, only the invasive species built specific interior structures which change over time. Our study leads to a hypothesis of optimal chamber number, which balances colony wood consumption against nest functionality. The constructions could play a role for environmental homeostasis that seems not necessary for the native species.

Keywords: animal architecture, tomography, Reticulitermes flavipes, $R$. grassei, self-organized structures, social insects 
Animals can create controlled microhabitats using self-made structures. The most impressive are the nests of social insects (i.e., ants, bees, wasps, and termites). Some termite mounds rise higher than 10 meters, which is more than 1,000 times the height of a worker. Even more intriguing is that such nests are produced without individual workers using any sort of collective "blueprint" (Buhl et al. 2005; Deneubourg and Franks, 1995). Social insects have achieved remarkable ecological success and dominance (Hölldobler and Wilson, 1990), perhaps due in part to their nests, which provide benefits in terms of defense, shelter (Traniello and Leuthold, 2000), controlled microclimatic conditions (e.g., air composition [ants: Bollazzi et al. 2012], temperature and humidity [termites: Ruelle 1964]), structure, and, in some cases, food. Indeed, certain subterranean termite species also consume the wood in which they live (Grassé 1984). These species serve as excellent models for studying nest development as they must trade-off between food consumption (wood) and environmental homeostasis. Part of this process is controlling the number and size of both tunnels and chambers. Thus, nest architecture may play an important role in regulating colony activity.

However, subterranean lifestyle makes it difficult to characterize nest structure. Previous studies, which analyzed nest architectures in several insect species, have largely employed destructive methods such as fragmentation (Bouillon 1964), step-by-step excavation (King and Spink 1969; Rabeling et al. 2007; Tschinkel 1999), the tracing of radioisotope-labeled foragers (Spragg and Paton 1980), or casts (i.e., latex [Garner 1953], cement [Bollazzi et al. 2012; Ruelle 1964], orthodontic plaster, wax, aluminum, zinc, or lead [Tschinkel 2010, 2011]). However, these approaches can only yield a temporal and/or spatial snapshot of the nest. They cannot provide information about structural dynamics, such as the growth of tunnel networks, nor can they be used to follow nest creation, wood consumption, and/or building activity over time. More recent studies, though, have begun utilizing computerized tomography (CT) scans to non-invasively visualize and characterize the architecture of social insect nests (ants [Halley et al. 2005; Khuong et al. 2016; Minter et al. 2012; Monaenkova et al. 2015]; bees [Greco et al. 2006]; termites [Darrouzet 2013; Eom et al. 2015; Fuchs et al. 2004; Himmi et al. 2014, 2016; Perna et al. 2008a,b]; wasps [Darrouzet 2013]; and hornets [Darrouzet 2013; Rome et al. 2015]). Using CT scans, it is possible to reconstruct a 3D structure via a series of 2D images; the structure's inhabitants are unharmed, even after several scans. Thanks to the images' high-contrast resolution, structural differences in physical density can be distinguished (see Sup. file Video 1). The ability of structures to block the X-ray beam can also be characterized. Nevertheless, despite their potential, longitudinal studies using CT scans have only been carried in ants (Linepithema humile: 7 or 8 scans over 6 months [Halley et al. 2005] and Lasius flavus: 8 scans over $48 \mathrm{~h}$ [Minter et al. 2012]). Their use may be tempered by the tool's main limitation: scanner size. It is impossible to analyze large structures.

An important requirement for the management of invasive species is to identify biological and ecological factors that influence their ability to establish and spread within a new environment, and how they present a significant advantage against native species. For example, Reticulitermes flavipes and $R$. grassei are subterranean termite species which live in sympatry along the French Atlantic coast, where their colonies exhibit important differences in their social organization, behavior, and breeding system (Perdereau et al. 2010, 2011, 2015). R. grassei is native to southwestern Europe (France and Spain). R. flavipes, in contrast, is an invasive species that is native to the eastern United States but that has spread to South America (Aber and Fontes 1993; Su et al. 2006) and Europe (Dronnet et al. 2006; see Evans 2013 for a review). Both species belong to the family Rhinotermitidae and, as such, share certain traits. Some studies demonstrated that $R$. flavipes has some advantages against $R$. grassei. For example, interspecific competition showed that $R$. flavipes was dominant over 
2011). Consequently, this competitive asymmetry may enable $R$. flavipes to become dominant in the environment. Interestingly, the main difference between the two species concerns their capacity to produce secondary neotenic reproductives. Genetic studies revealed that all French $R$. flavipes colonies produce more neotenics than $R$. grassei colonies (Leniaud et al, 2011). In such conditions, its interspecific superiority, its lack of intraspecific aggression, the production of numerous neotenics and large extensive colonies, seem to be some of the reasons for $R$. flavipes invasive success. Among these factors, nest-building dynamics, nest shapes and sizes, wood consumption dynamics are largely unknown for both species. However, information on nest dynamics is essential to understand the wood consumption dynamic and to assess the efficacy of the strategies used to control invasive termite infestations (Forschler 1994). For example, they both eat and live in nondecomposed wood. They are initially single-piece nesters, but they eventually move to a new piece of wood when their original nests have been completely consumed (Evans 2013). Both produce large subterranean colonies and are therefore ideal species for studying wood consumption.

In this study, we sought to discover if both Reticulitermes species build interior structures and thereby to discover the relationship between these constructions and the volume and dynamic of wood consumed. Doing so, we wanted to know whether the construction of the nest could participate to the invasive success of $R$. flavipes. As such species seems to produce larger colonies and numerous neotenics, we supposed that (1) wood consumption would be greater in the invasive species (to feed numerous individuals and more particularly neotenics), (2) $R$. flavipes workers would have greater capacities to build the nest, and consequently (3) nest structures from both species could present some differences in size and shape. Moreover, our study leads to a hypothesis of optimal chamber number, which balances colony wood consumption against nest functionality. We hypothesis that a cumulative Weibull distribution or a sigmoid function will appropriately models the biological process at work.

To test these hypotheses, we used CT scans to characterize nest creation, construction, and architecture as well as wood consumption over a ten-month period in experimental fragment colonies of both species in the same experimental conditions. More specifically, we exploited CT scans to investigate (1) nest construction dynamics, (2) wood consumption, and (3) intercolonial variation in both.

\section{Materials and Methods}

\section{Colony rearing conditions}

Reticulitermes colonies were collected from wood fragments and pine tree stumps in the St. Trojan forest on Oléron Island (Charente-Maritime, France). They were identified to species using cuticular hydrocarbon profiles (Bagnères et al. 1990, 1991). For the duration of the experiment, colonies were kept at $26{ }^{\circ} \mathrm{C}$ in full darkness. We then filled plastic boxes $(18 \times 12 \times 7 \mathrm{~cm})$ with moist Fontainebleau sand (very fine, homogeneous granularity); sand depth was $2 \mathrm{~mm}$. We added a block of untreated pine (12 x $4 \times 4 \mathrm{~cm})$ as a food source. The sand was moistened every day. Four fragment colonies of $R$. grassei and six fragment colonies of $R$. flavipes were introduced into separate boxes; each contained 900 workers and was taken from a different fieldcollected colony.

\section{Computerized $X$-ray tomography scan analysis}

To monitor wood consumption, each plastic box was subject to CT scans (120 keV, $180 \mathrm{mAs})$ using a Phillips Brillance CT 40 medical scanner, made available to us by the Neuroradiology Department at the Tours Hospital (Tours, France). We obtained a series of virtual vertical "slices" through the box (thickness of $0.67 \mathrm{~mm}$, increments of $0.33 \mathrm{~mm}$ ) (Fig. 1a and Sup file 1). The boxes were scanned before the termites were introduced 

days (T4), 100 days (T5), 202 days (T6, Sup file video 1), and 258 days (T7).

Then, we analyzed each series of CT scans (DICOM standard; Fig. 1a, Sup file video 1) using OsiriX v. 4.19 image processing software (Darrouzet, 2013; Rosset et al. 2004), which is designed to allow 3D volumes to be reconstructed from large sets of multidimensional and multimodality images (Fig. 1b,c and Sup file video 2). Areas of wood consumption, which we called "regions of interest" (ROIs), were identified manually on each image and measured (Fig. 1a). We thus obtained precise information about ROI size, shape, and boundaries. We were also able to observe nest architecture over time, namely changes in tunnels (interior and exterior), chamber number, wood consumption volume, and interior structures. One of the R. grassei colonies died between T5 and T6, but we used the data available from T0 to T5.

\section{Statistics}

Our statistical analyses were performed using SigmaStat (v. 10.0.054). In all cases, data normality was first assessed using Kolmogorov-Smirnov tests. In the results, means are presented with standard errors. To compare the locations where the two species initially attacked the wood pieces, t-tests (normally distributed data) and Mann-Whitney rank sum tests (non-normally distributed data) were used. To assess differences in chamber volume and number across time for the two species, two-way repeated measures ANOVAs was used; $a$ posteriori pairwise comparisons were performed using Holm-Sidak tests.

To test if the data is suitable for a regression analysis we used a Kolmogorov-Smirnov test for a normally distributed population and a constant variance test by computing the Spearman rank correlation between the absolute values of the residuals and the observed value of the dependent variable. To gauge the ability of the regression equation to predict the dependent variable, an ANOVA (F test) was performed. To provide a measure of how well the number of chamber is dependent of the volume consumed, the coefficient of determination $\left(\mathrm{r}^{2}\right)$ was used.

\section{Results}

Nest creation

During the nest-creation period (T1 and T2), there was no clear pattern in the way the termites attacked the wood (Mann-Whitney U Statistic, $\mathrm{P}=0.33$ ): they targeted both the bottom face of the block (R. grassei, $\mathrm{n}=50$; $R$. flavipes, $\mathrm{n}=34$ ) and the exposed faces of the block ( . grassei, $\mathrm{n}=50 ; R$. flavipes, $\mathrm{n}=14$ ). The first exterior tunnels, made of sand, wood, and fecal pellets, were observed after 51 days; these afforded protection to the termites. From that point on, it was rare to observe an attack that was not associated with a sand tunnel $(R$. grassei, $\mathrm{n}=9 ;$. flavipes, $\mathrm{n}=6)$, as most of the new chambers were initiated from inside the tunnels ( $R$. grassei, $\mathrm{n}=215 ;$ R. flavipes, $\mathrm{n}=684)$, or via the extension of other chambers (R. grassei, $\mathrm{n}=188 ; R$. flavipes, $\mathrm{n}=253)$. The two species did not differ in their overall approach (T3 and T7; $\mathrm{t}=-0.994 ; \mathrm{P}=0.359)$ (Fig. 2).

\section{Wood consumption}

As they ate through the wood, the termites generated living space for themselves. We identified 1,829 ROIs across the 10 study colonies; their mean size was $0.43 \mathrm{~cm}^{3}$ (range: $0.0004-10.25 \mathrm{~cm}^{3}$ ). Most ROIs were small $\left(50 \%<0.111 \mathrm{~cm}^{3}\right.$ and $\left.90 \%<1.196 \mathrm{~cm}^{3}\right)($ Fig. 3).

At each time point, the two termite species had equivalent chamber numbers (two-way repeated measures ANOVA: $\mathrm{F}=1.287, \mathrm{df}=1, \mathrm{P}=0.289)$ after accounting for differences in the factor times $(\mathrm{F}=0.648, \mathrm{df}=7$, $\mathrm{P}=0.714$ ). Both species appeared to go through three phases of wood consumption (Fig. 4; $\mathrm{F}=37,945$, $\mathrm{df}=7$, 
181

$\mathrm{P}<0.001$ ): there were no differences in chamber number at T0, T1, and T2 (phase one), at T3 and T4 (phase two), and at T5, T6, and T7 (phase three). During the first phase, a small number of new chambers were made. During the second phase, chamber creation accelerated. During the third phase, chamber creation declined (Fig. 4). By the end of the experiment, both species had generated almost the same number of chambers. R. flavipes nests contained between 33 and 64 chambers, while R. grassei nests contained between 24 and 53 chambers (Fig. 4).

There also did not appear to be interspecific differences in wood consumption over time (T0 to T7; twoway repeated measures ANOVA: $\mathrm{F}=0.774, \mathrm{P}=0.404$ ). At the end of the experiment (i.e., after 258 days), $R$. flavipes colonies had eaten $15.10-43.66 \mathrm{~cm}^{3}$ of wood, corresponding to a mean $15.51 \% \pm 2.068$ of total wood block volume (Fig. 4). R. grassei had eaten $21.19-32.26 \mathrm{~cm}^{3}$ of wood, corresponding to a mean $14.2 \% \pm 1.83$ of total wood block volume (Fig. 4). While the volume of wood consumed was equivalent between species at each time point, the mean consumption across time for species was different (two-way repeated measures ANOVA: $\mathrm{F}=73,347, \mathrm{P}<0.001)$. Within species, all pairwise comparisons between time points were statistically significant, except during the first stage (T0 vs. T1, T0 vs. T2, and T1 vs. T2) and for T3 versus T4 (Fig. 4).

Chamber number was related to the percentage of wood volume consumed in both species (R. flavipes: $\mathrm{r}^{2}=0.979$, $\mathrm{F}=65.07, \mathrm{P}=0.0008 ;$ grassei: $\mathrm{r}^{2}=0.984, \mathrm{~F}=84.27, \mathrm{P}=0.0005$; Fig. 5 ). The best fit for the data was a fourparameter non-linear regression model with $\mathrm{f}(\mathrm{x})=\mathrm{y}_{0}+\mathrm{a} /\left(1+\exp ^{(-(\mathrm{x}-\mathrm{x} 0) / \mathrm{b})}\right)$. The equations were as follows:

$$
\text { R.grassei } \quad y=-2.2+\frac{39.80}{\left.\left(1+e^{(-(x-3.85) / 1.24}\right)\right)}
$$

$$
\text { R.flavipes } \quad y=-0.22+\frac{47.98}{\left(1-e^{(-(x-3.85) / 1.72)}\right)}
$$

with $\mathrm{x}=$ percentage of wood volume consumed, $\mathrm{y}=$ chamber number, $\mathrm{a}=$ the minimum value that can be obtained (i.e. when $\mathrm{x}=0$ ) and $\mathrm{b}=$ Hill's slope of the curve. An Anova was used accordingly, demonstrating that the volumes of wood consumed by both species contribute to the prediction of the number of chamber observed in the nests.

\section{Interior structures}

Only $R$. flavipes seemed to have the ability to generate and modify interior architectural structures such as pillars, ceilings/floors, tunnels, and inner/outer walls (Fig. 2). The timing was colony specific: the first example of such structures occurred after 20 days in one colony (Fig. 8), but after 258 days in another colony. By the end of the experiment, a mean of $14.5 \pm 7$ interior structures were present in $R$. flavipes nests. Although there was marked intercolonial variability, there was a strong correlation between the number of days that had passed and the number of such structures $\left(r^{2}=0.992\right.$, Anova $\mathrm{F}=747.39, \mathrm{P}=0.0001$; Fig. 8). There was a significant relationship between the number of interior structures and the number of chambers $\left(r^{2}=0.974 ; F=50.45\right.$; $\mathrm{P}=0.0012$; Fig. 9). The best fit for the data was a four-parameter equation (Weibull distribution), where $\mathrm{x}=$ the number of constructions:

$$
y=47.27\left(1-e^{(-(x+70.4) / 22.29)^{10.03}}\right)
$$


This study used CT scans (X-ray tomography) to provide the first detailed quantitative descriptions of Reticulitermes nests dynamics. We obtained new information about nest creation, the dynamics of wood consumption, the creation of chambers and tunnel networks, and shifts in interior architecture. Because initial conditions were standardized (i.e., wood block size and colony size), we were able to characterize and compare these features over time.

More specifically, we collected data on two sympatric Reticulitermes species, one native and one invasive, which has helped enhance our understanding of their natural histories. First, we saw no interspecific differences in the volume of wood consumed or in the number of chambers created. Second, we observed three phases of wood consumption. Over the first 25 days of the experiment (Phase 1), wood consumption was low. Then, the first exterior tunnels appeared, wood consumption accelerated, and a large number of small chambers were created (Phase 2). Finally, 200 days into the experiment, the speed of wood consumption remained unchanged, but a slightly smaller number of chambers were generated. However, these chambers were either larger or the product of fusion.

By eating wood and engaging in building activity over a several-month period, termites can create networks of interconnected galleries and chambers in which they live and through which they can travel (Grassé 1984, also see Sup file video 1 and 2). Within the nest, termites are also protected from predators and climatic extremes. Nonetheless, a major challenge remains: sufficient ventilation (Ohashi et al. 2012). Air quality within the nest can be compromised by colony respiration, namely the production and release of $\mathrm{CO}_{2}$ (Risch et al. 2012). In general, ventilation systems are passive, driven by temperature or velocity gradients in air currents (Wenzel 1990). Indeed, termites are well known for their ability to regulate nest conditions, including temperature and humidity (Lüscher 1955; Korb and Linsenmair 2000; Korb 2003; see also Turner 2001 for a review). The construction of different interior structures could help enhance air flow and thus improve air quality. To this end, nest configurations might need to remain dynamic. The small size of most of the chambers observed in this study could be the product of a trade-off between wood consumption, colony defense, and environmental homeostasis. As colonies grow, old chambers can be rearranged and new chambers can be created: here, we observed that some chambers increased in size or fused.

One of our notable results is that, although both species displayed similar levels of wood consumption and created exterior tunnels, only $R$. flavipes built interior structures. These included pillars, ceilings/floors, and walls (Fig. 1b). Like Cubitermes species (Perna et al. 2008a), R. flavipes could adjust interior nest architecture by adding and modifying the number of interior structures, depending on chamber number or wood consumption. Ceilings and floors appeared in the largest chambers, and some old entrances were sealed off. Since colonies were given just one piece of wood, termites were forced to eat where they lived. Consequently, for $R$. flavipes, such structures may be part of the trade-off between wood consumption, colony defense, and environmental homeostasis. In our experiment, however, exterior temperature and humidity were kept constant, and the termites were enclosed in boxes, preventing any air movement. Although both species were collected from the same area and thus experienced the same environmental conditions, it could be that $R$. grassei, the native species, did not build interior structures because laboratory conditions were acceptable. Perhaps this was not the case for $R$. flavipes, the invasive species, which may have needed to manage nest ventilation. Perna et al. (2008a) showed that, in Cubitermes species, final nest topology reflects a compromise between efficiency and defense. The same could be true in Reticulitermes species. Furthermore, it could be that $R$. flavipes utilizes interior structures to help defend against predators in its native range within North America and that this 
behavior was conserved within its introduced range in France. However, R. flavipes' potential natural predators remain unidentified.

Another hypothesis for the interspecific difference in the use of interior structures could be linked to the production of neotenics. More specifically, $R$. flavipes may produce more neotenics than $R$. grassei: Leniaud et al. (2011) observed that, after one year, 100\% of $R$. flavipes groups (composed of workers) had produced neotenics, while just $63 \%$ of $R$. grassei groups had done the same. Compared to $R$. grassei, $R$. flavipes produced significantly more offspring because female numbers and productivity were both higher. Here, consequently, our $R$. flavipes colonies may have been more densely populated than our $R$. grassei colonies after just a few months. Higher densities could have led to higher $\mathrm{CO}_{2}$ concentrations and thus triggered the implementation of a ventilation system mediated via interior structures. It is also conceivable that $R$. flavipes neotenics are more sensitive to certain environmental conditions, requiring more intensive nest management. Unfortunately, because we did not assess the characteristics of our colonies at the end of the study, additional research is needed to test these hypotheses.

In our study, there was noticeable intercolonial variation in nest configuration (Sup File 1), even though nests presumably share the same functional purpose and both colony numbers and wood consumption levels were similar. There were no interspecific differences in chamber organization. Nest initiation was also similar. Although the colonies attacked the wood block at different locations, all their entrance cavities were excavated in the springwood and the network expanded along the wood's microstructure. This pattern is evident on CT scans (Fig 1c) because the degree of X-ray absorption is correlated with wood density, which is greatest for the annual growth rings (Himmi et al. 2016). We found that both termite species generally excavated tunnels and chambers in softer wood (Sup file 2). This particular behavior is known to be affected by wood chemistry (Abe and Higashi 1991) and nutritional value (Shellman-Reeve 1994). Only a few tunnels crossed harder wood to reach softer areas, which allowed nest development.

Taken together, our results suggest that $R$. grassei and $R$. flavipes differ in their nest-building design. This study confirms that both the environment and the termites themselves can influence the expression of extended phenotypes, such as nest configuration. Although substrate quality (e.g., winter/summer wood) can influence nest architecture making them nest specific, while, building behavior is species specific. This study also underscores the utility of $\mathrm{CT}$ scans as a non-invasive technique for following wood consumption and nest architecture in termites over time and the expression of extended phenotypes. Indeed, the types of data it yields could be used in future research efforts to model nest construction dynamics.

\section{Acknowledgments}

We gratefully acknowledge J. Pearce for her English revisions. We would like to thank S. Dupont for rearing the termite colonies in the laboratory and D. Herbreteau for letting us use the CT scanner at Tours Hospital.

\section{References}

Abe T, Higashi M (1991) Cellulose centred perspective on terrestrial community structure. Oikos 60:127-133

Aber A, Fontes LR (1993). Reticulitermes lucifugus (Isoptera,Rhinotermitidae), a pest of wooden structures, is introduced into the South American Continent. Sociobiology 21:335-339.

Bagnères A-G, Clément J-L, Blum M, Severson R, Joulie C, Lange C (1990). Cuticular hydrocarbons and defensive compounds of Reticulitermes flavipes (Kollar) and R. santonensis (Feytaud): polymorphism and chemotaxonomy. J Chem Ecol 16:3213-3244 
Bagnères A-G, Killian A, Clément J-L, Lange C (1991). Interspecific recognition among Termites of the genus Reticulitermes. Evidence for a role for the cuticular hydrocarbons. J Chem Ecol 17:2397-2420

Bollazzi M, Forti LC, Roces F (2012). Ventilation of the giant nests of Atta leaf-cutting ants: Does underground circulating air enter the fungus chambers? Insectes Soc. 59(4):487-498

Bouillon A (1964). Structure et accroissement des nids d'Apicotermes Holmgren (Isoptere, Termitinae). 295326pp. In: Etudes sur les termites Africains. A. Bouillon (Eds), Université de Léopoldville.

Buhl J, Deneubourg JL, Grimal A, Theraulaz G (2005). Self-organized digging activity in ant colonies. Behav Ecol and Socio 58(1):9-17

Darrouzet E (2013). Les insectes bâtisseurs : nids de termites, de guêpes et de frelons. Connaissances \& Savoirs (Eds).

Deneubourg JL, Franks NR (1995). Collective control without explicit coding: The case of communal nest excavation. J Insect Behav 8(4):417-432

Dronnet S, Lohou C, Christidès J-P, Bagnères A-G (2006). Cuticular hydrocarbon composition reflects genetic relationship among colonies of the introduced termite Reticulitermes santonensis Feytaud. J Chem Ecol 30:1027-1042

Eom Y-H, Perna A, Fortunato S, Darrouzet E, Theraulaz G, Jost C (2015). Network based model of the growth of termite nests. Phy Res E 92(6): 062810

Evans TA, Forschler BT, Kenneth G (2013). Biology of invasive Termites: A worldwide review. Annu Rev Entomol 58:455-74

Forschler BT (1994), Fluorescent spray paint as a topical marker on subterranean termites (Isoptera: Rhinotermitidae). Sociobiology, 24, pp. 27-38

Fuchs A, Schreyer A, Feuerbach S, Korb J (2004). A new technique for termite monitoring using computer tomography and endoscopy. Inter J Pest Manag 50(1):63-66

Garner M R (1953). The Preparation of Latex Casts of Soil Cavities for the Study of Tunneling Activities of Animals. Science, 118(3066):380-381

Grassé PP (1984). Termitologia. Fondation des sociétés - Construction. Tome2. Paris: Masson.

Greco M, Bell M, Spooner-Hart R, Holford P (2006). X-ray computerized tomography as a new method for monitoring Amegilla holmesi nest structures, nesting behaviour, and adult female activity. Entomol Exp et App 120(1):71-76

Halley JD, Burd M, Wells P (2005). Excavation and architecture of Argentine ant nests. Insectes Soc. 52(4):350356

Himmi SK, Yoshimura T, Yanase Y, Oya M, Torigoe T, Imazu S (2014). X-ray tomographic analysis of the initial structure of the royal chamber and the nest-founding behavior of the drywood termite Incisitermes minor. J Wood Science 60(6):453-460

Himmi SK, Yoshimura T, Yanase Y, Mori T, Torigoe T, Imazu S (2016). Wood anatomical selectivity of drywood termite in the nest-gallery establishment revealed by X-ray tomography. Wood Science Tech 50(3):631-643

Hölldobler B, Wilson E (1990). Colony Odor and Kin Recognition. In The Ants (pp. 197-199).

Khuong A, Gautrais J, Perna A, Sbaï C, Combe M, Theraulaz G (2016). Stigmergic construction and topochemical information shape ant nest architecture. PNAS 113(5):201509829

King EG, Spink WT (1969). Foraging Galleries of the Formosan Subterranean Termite, Coptotermes formosanus, in Louisiana. An Entomol Soc Am 62(3):536-542 
Korb J, Linsenmair KE (2000) Thermoregulation of termite mounds: what role does ambient temperature and metabolism of the colony play? Insectes Soc. 47:357-363

Korb J (2003). Thermoregulation and ventilation of termite mounds. Naturwissneschaften 90:212-219

Leniaud L, Darrouzet E, Dedeine F, Ahn K, Huang Z, Bagnères A-G (2011). Ontogenic potentialities of the worker caste in two sympatric subterranean termites in France. Evol Dev 13:138-148

Lüscher M, (1955). Der Sauerstoffverbrauch bei Termiten und die Ventilation des Nestes bei Macrotermes natalensis (Haviland). Acta Trop 12:289-307

Minter NJ, Franks NR, Robson Brown KA (2012). Morphogenesis of an extended phenotype: four-dimensional ant nest architecture. J Royal Soc Interface 9(68):586-595

Monaenkova D, Gravish N, Rodriguez G, Kutner R, Goodisman MD, Goldman, DI. (2015). Behavioral and mechanical determinants of collective subsurface nest excavation. J. Exp. Biol. 218, 1295-1305. doi:10.1242/jeb.113795.

Ohashi M, Domisch T, Finér L, Jurgensen MF, Sundström L, Kilpeläinen J, Risch AC, Niemelä P (2012). The effect of stand age on $\mathrm{CO} 2$ efflux from wood ant (Formica rufa group) mounds in boreal forests. Soil Biol. Biochem 52:21-28

Perna A, Jost C, Couturier E, Valverde S, Douady S, Theraulaz G (2008a). The structure of gallery networks in the nests of termite Cubitermes spp. revealed by X-ray tomography. Naturwissenschaften 95(9):877-884

Perna A, Valverde S, Gautrais J, Jost C, Solé R, Kuntz P, Theraulaz G (2008b). Topological efficiency in threedimensional gallery networks of termite nests. Physica A: Stat Mech App 387(24):6235-6244

Perdereau E, Bagnères AG, Dupont S, Dedeine F. (2010). High occurrence of colony fusion in a European population of the American termite Reticulitermes flavipes. Insectes sociaux, 57(4), 393-402.

Perdereau E, Dedeine F, Christidès JP, Dupont S, Bagnères AG. (2011). Competition between invasive and indigenous species: an insular case study of subterranean termites. Biological Invasions, 13(6), 14571470.

Perdereau E, Bagnères AG, Vargo EL, Baudouin G, Xu Y, Labadie P, Dupont S, Dedeine F. (2015). Relationship between invasion success and colony breeding structure in a subterranean termite. Molecular ecology, 24(9), 2125-2142.

Rabeling C, Verhaagh M, Engels W (2007). Comparative study of nest architecture and colony structure of the fungus-growing ants, Mycocepurus goeldii and M. smithii. J Insect Sci 7(40):1-13

Risch AC, Anderson TM, Schütz M (2012). Soil CO2 emissions associated with termitaria in Tropical savanna: evidence of hot-spot compensation. Ecosystems 15:1147-1157

Rome Q, Muller FJ, Touret-Alby A, Darrouzet E, Perrard A, Villemant C (2015). Caste differentiation and seasonal changes in Vespa velutina (Hym.: Vespidae) colonies in its introduced range. J App Entomol 139(10):771-782

Rosset A, Spadola L, Ratib OJ (2004). OsiriX: An Open-Source Software for Navigating in Multidimensional DICOM Images. Digit Imaging 17:205

Ruelle J (1964). L'Architecture du nid de Macrotermes natalensis et son sens fonctionnel. In A. Bouillon (Ed.), Etudes sur les termites Africains. Université de Léopoldville.

Shellman-Reeve JS (1994) Limited nutrients in a dampwood termite: nest preference, competition and cooperative nest defence. J Anim Ecol 63:921-932

Spragg WT, Paton R (1980). Tracing, Trophallaxis and Population Measurement of Colonies of Subterranean Termites (Isoptera) Using a Radioactive Tracer. An Entomol Soc Am 73(6):708-714 

morphology. An Entomol Soc Am 99(2): 352-363

Traniello JFA, Leuthold RH (2000). Behavior and Ecology of Foraging in Termites. In: Abe Takuya, Bignell David Edward, Higashi Masahiko, editors. Termites: Evolution, Sociality, Symbioses, Ecology. Dordrecht: Springer Netherlands. Kluwer Academic Publishers; 2000. p. 141-68

Tschinkel WR (1999). Sociometry and sociogenesis of colony-level attributes of the Florida harvester ant (Hymenoptera: Formicidae). An Entomol Soc Am 92(1):80-89

379 Tschinkel WR (2010). Methods for casting subterranean ant nests. J Insect Sc 10(1)

380 Tschinkel WR (2011). Back to basics: sociometry and sociogenesis of ant societies (Hymenoptera: Formicidae). Myrmecol News 14:49-54

Turner JS (2001). On the mound of Macrotermes michaelseni as an organ of respiratory gas exchange. Phys Biochem Zool 74(6):798-822

Wenzel JW (1990). Nest design and secondary functions of social insect architecture. In G.Veeresh, B. Mallick, C. Viraktamath (Eds.), Social insects and the environment (pp. 657-658). 
389 Figure 1. Two-dimensional DICOM scans of Reticulitermes nests. Locations in which wood had been consumed

390

391

392

393

394

395

396

397

398

399

400

401

402

403

404

405

406

407

408

409

410

411

412

413

414

415

416

417

418

419

420

421

422

423

424

(regions of interest: ROIs) were traced manually (dotted line below). Their areas were then calculated (white shapes below).

Figure 2. On the left is a three-dimensional image showing the exterior tunnels performed by $R$. flavipes termites. In the center and on the right are two-dimensional images of interior structures (red circle: cap; orange oval: wall; yellow circle: pillar) made with sand. Softer wood (i.e., of lower density) is black or gray, while harder wood (i.e., of higher density) is white.

Figure 3. Three-dimensional images of R. grassei nests, where sand-based and wood-based structures can be distinguished (yellow vs. brown, respectively). Here, areas in which wood is present (i.e., based on density values) have been artificially removed to allow the chambers (white) to be more easily observed.

Figure 4. Percentage of attacks at different locations on the wood blocks for the two termite species. The percentages were calculated using all the observations from all the colonies. The "outer sides" were the exposed faces of the block. The "underside" was the face in contact with the ground. "Interior" indicates chambers built from an earlier chamber. "After tunneling" indicates attacks initiated from within a sand tunnel that targeted the sides of the block.

Figure 5. Species-specific distributions of ROI volume

Figure 6. Boxplots of chamber number (light gray bars), volume of wood consumed (dark gray bars), and the percentage of the total wood consumed (dark line) over time in nests built by $R$. grassei (upper graph) and $R$. flavipes (lower graph). Within the boxes, the solid white lines are the means and the solid black lines are the medians.

Figure 7. Relationship between chamber number and the percentage of wood consumed for R. grassei (gray) and $R$. flavipes (black). The solid lines represent the best-fit regression lines, and the dotted lines indicate the $95 \%$ confidence intervals.

Figure 8. Number of interior structures built by $R$. flavipes over time (means $\pm \mathrm{SE}$ ). The solid black line is the best-fit regression line, and the dotted gray lines indicate the $95 \%$ confidence interval.

Figure 9. Relationship between chamber number and interior structure number for $R$. flavipes (means $\pm \mathrm{SE}$ ). The solid black line is the best-fit regression line, and the dotted gray lines indicate the $95 \%$ confidence interval. 


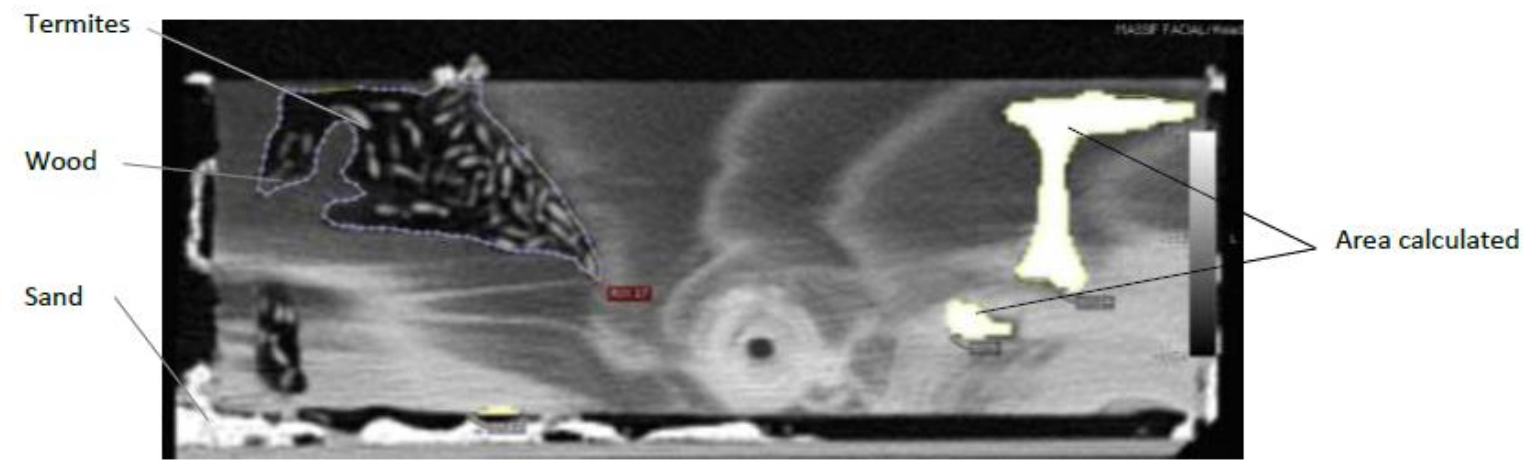

Figure 2
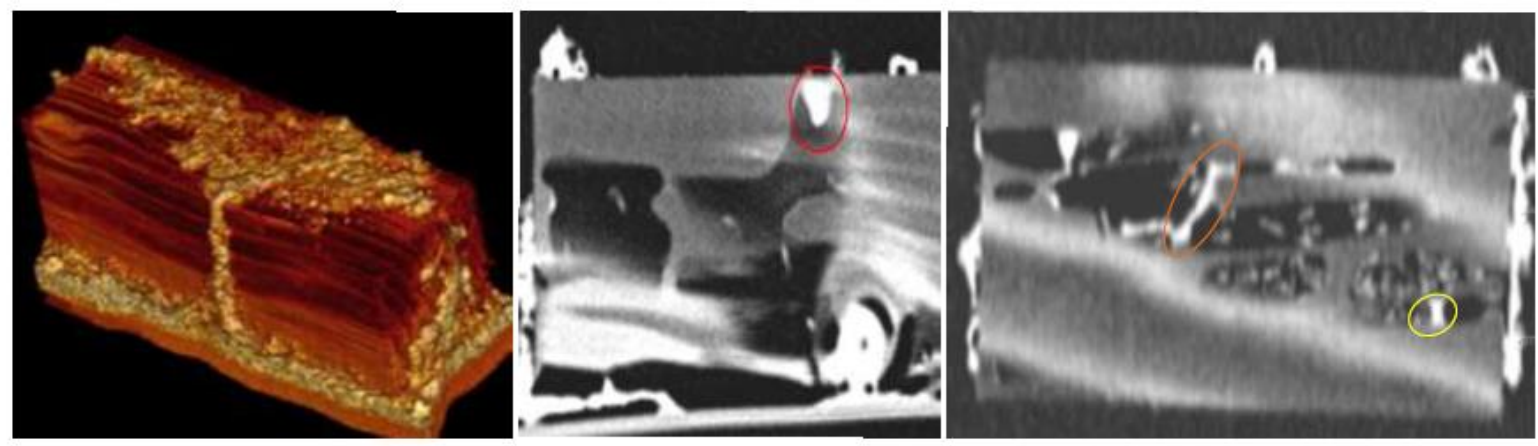

429

430

431

Figure 3

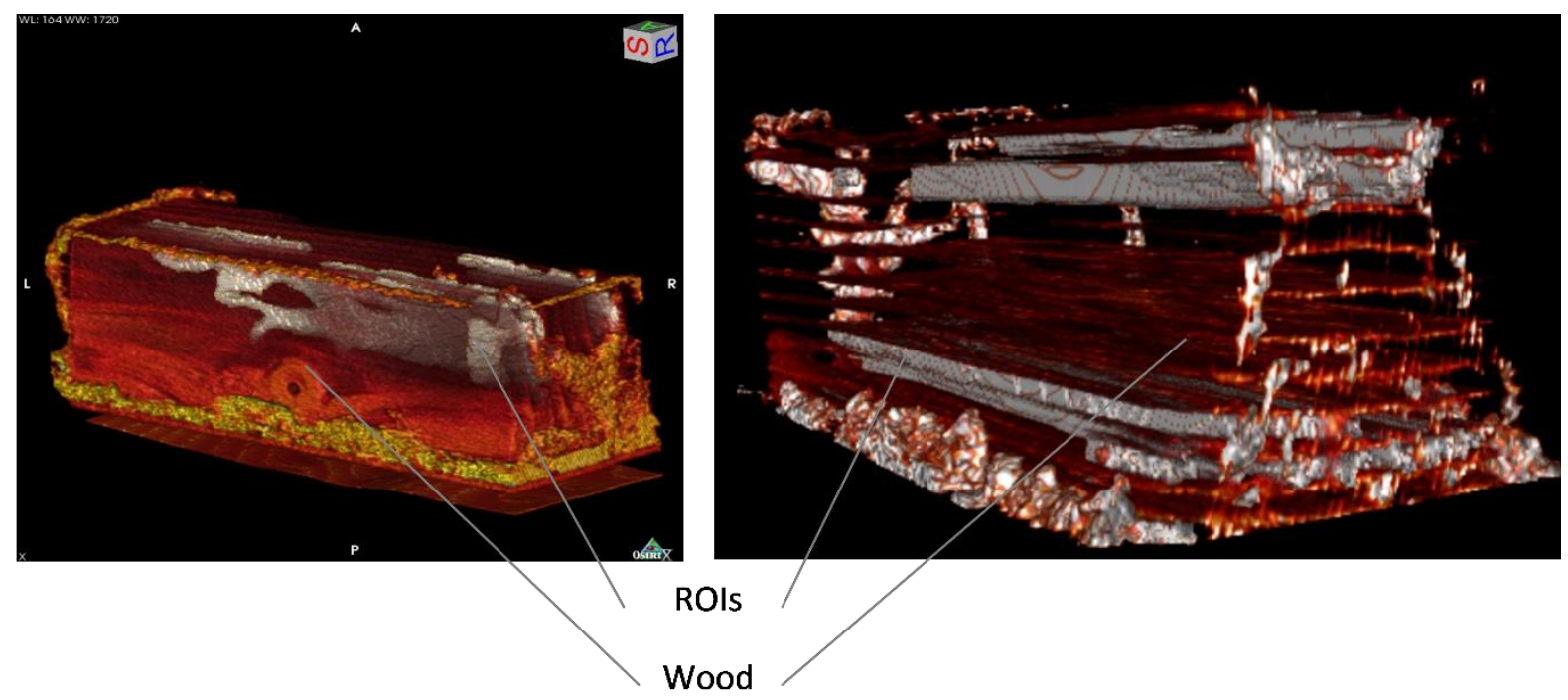

432 


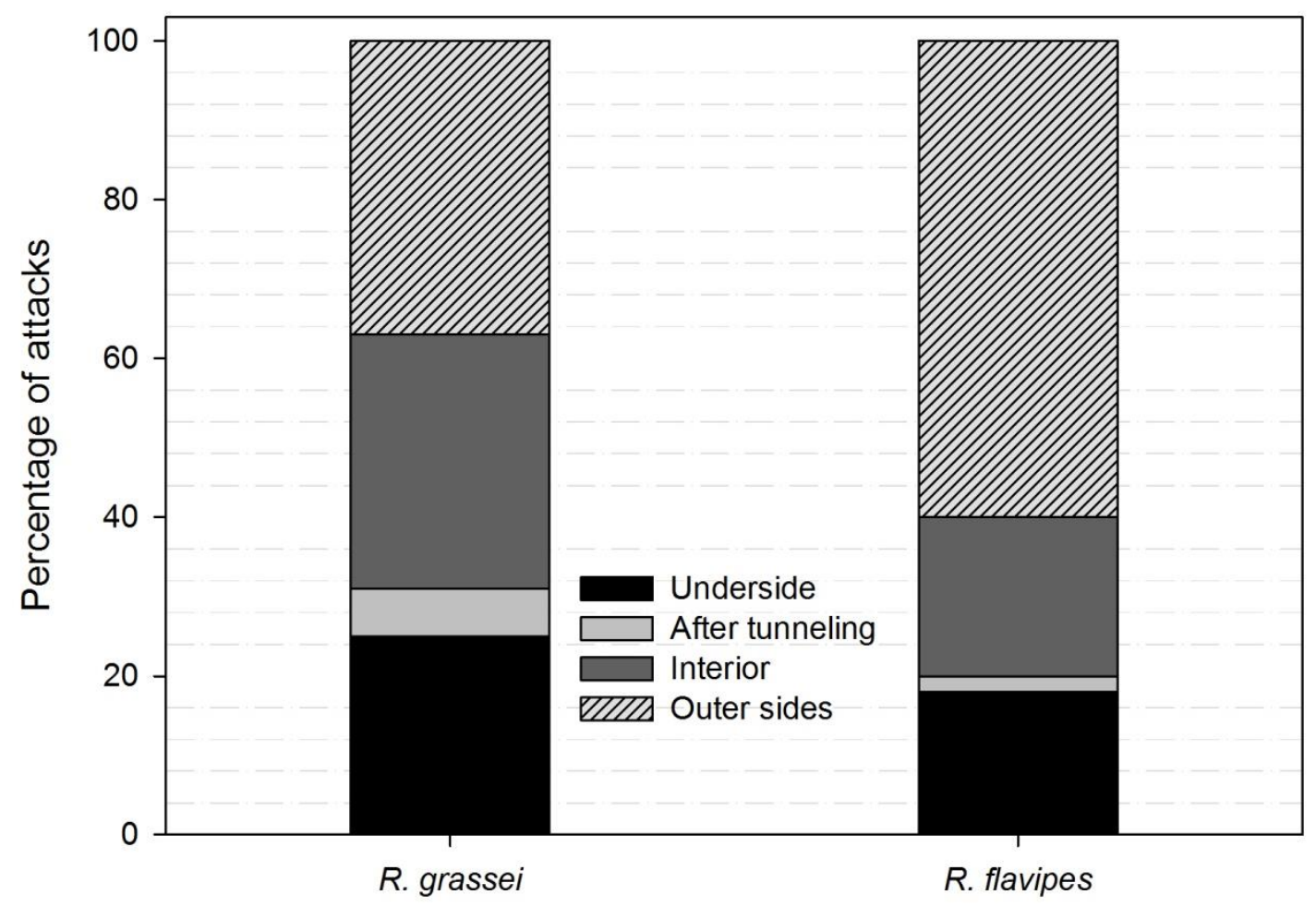

435

436

437

438 Figure 5
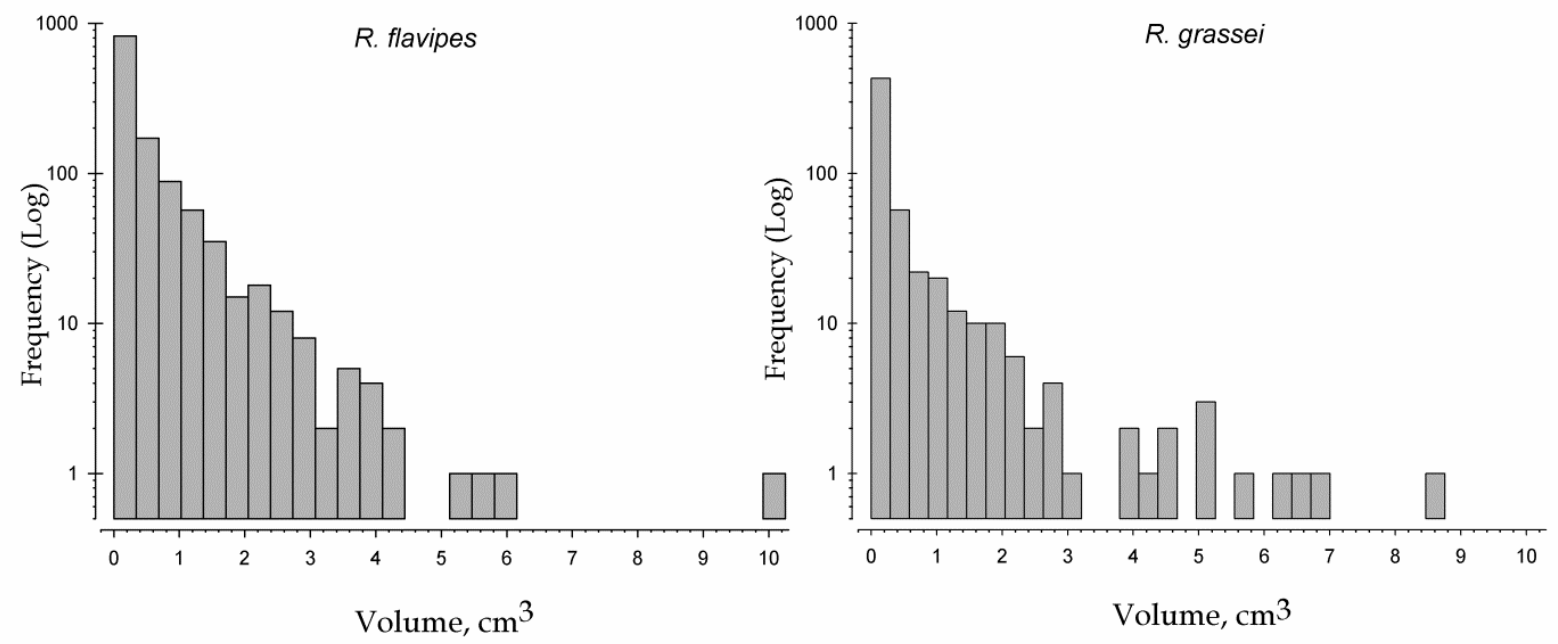

439

440

441 


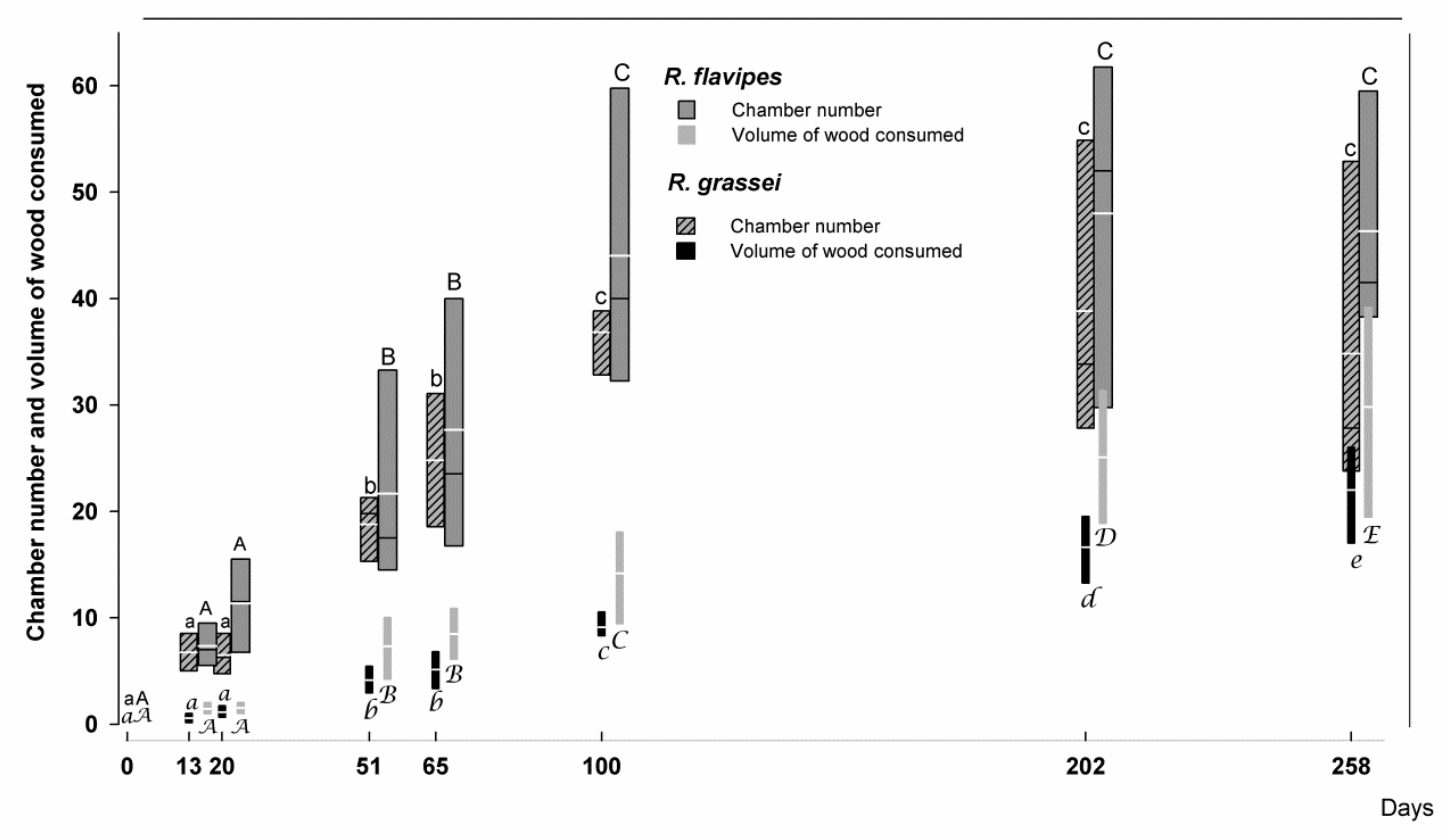




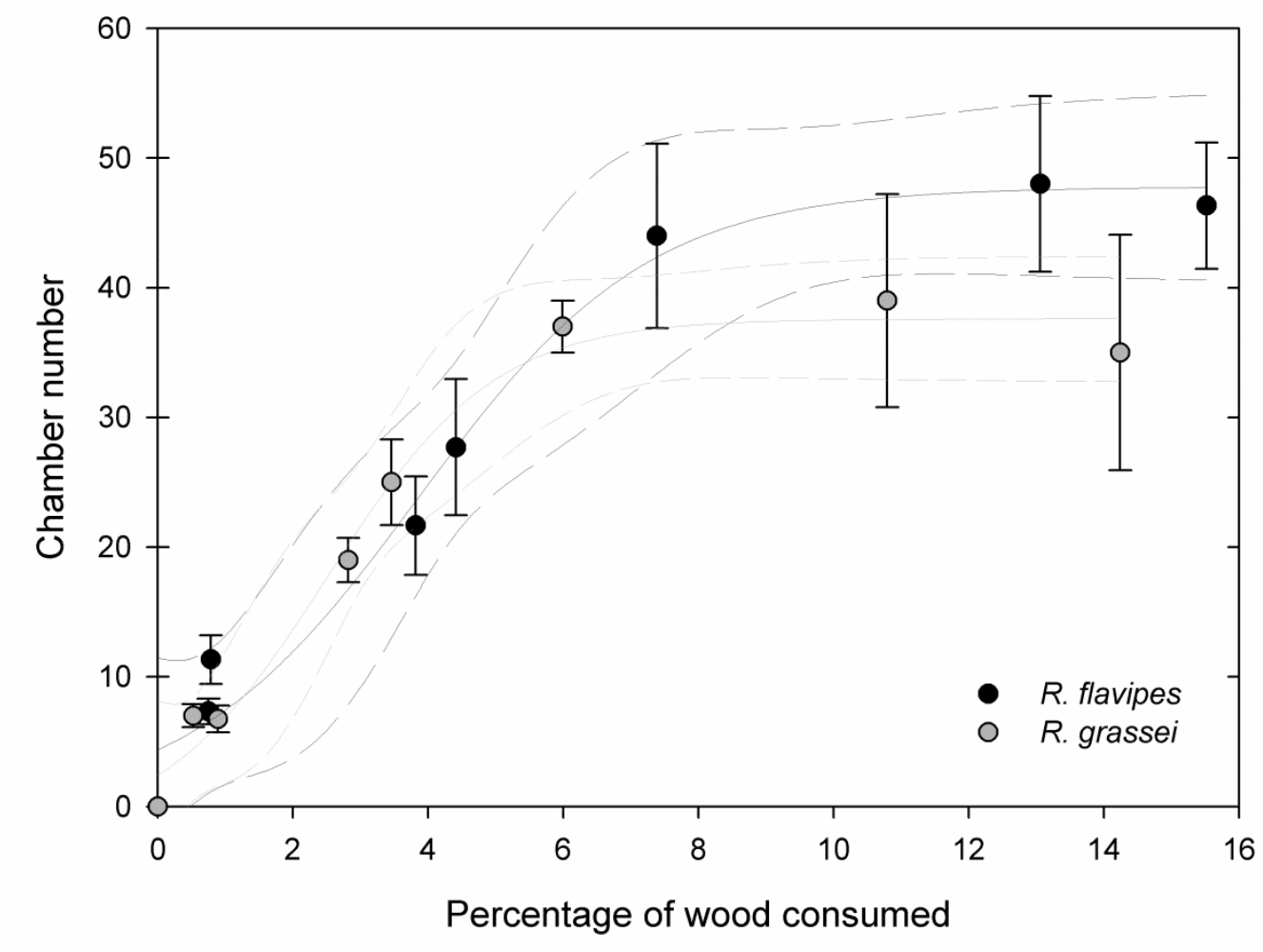

447

$448 \quad$ Figure 8

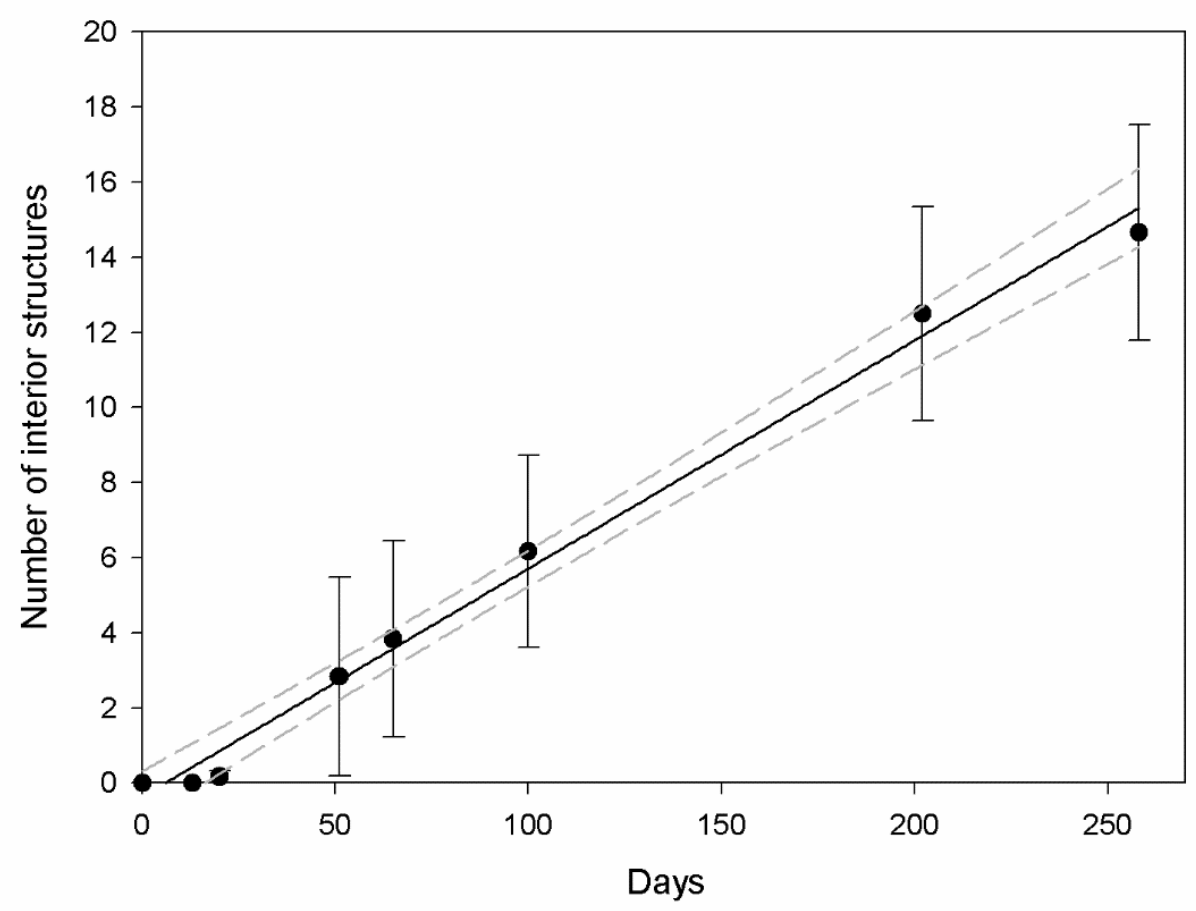




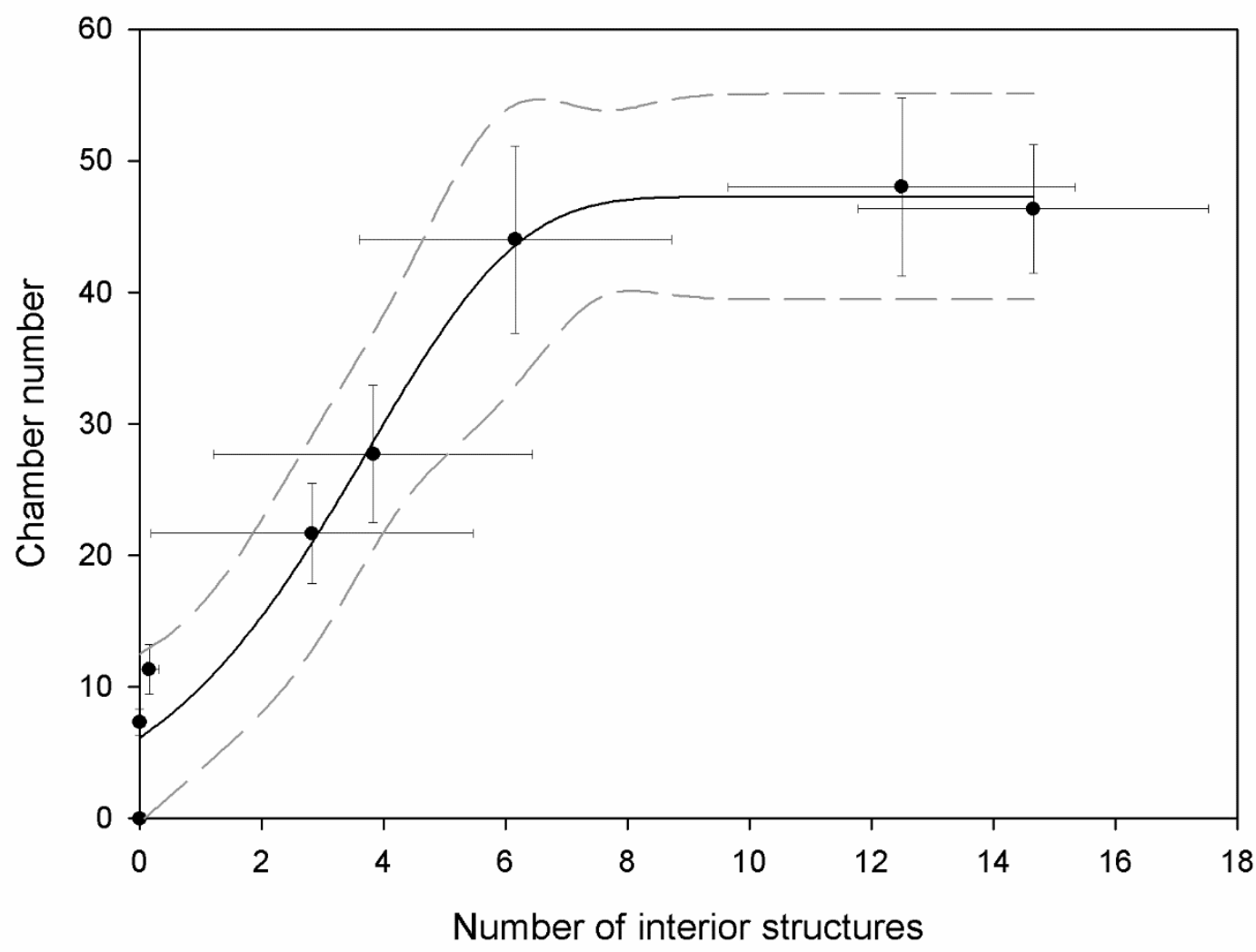

453 
Figure 1

ROI

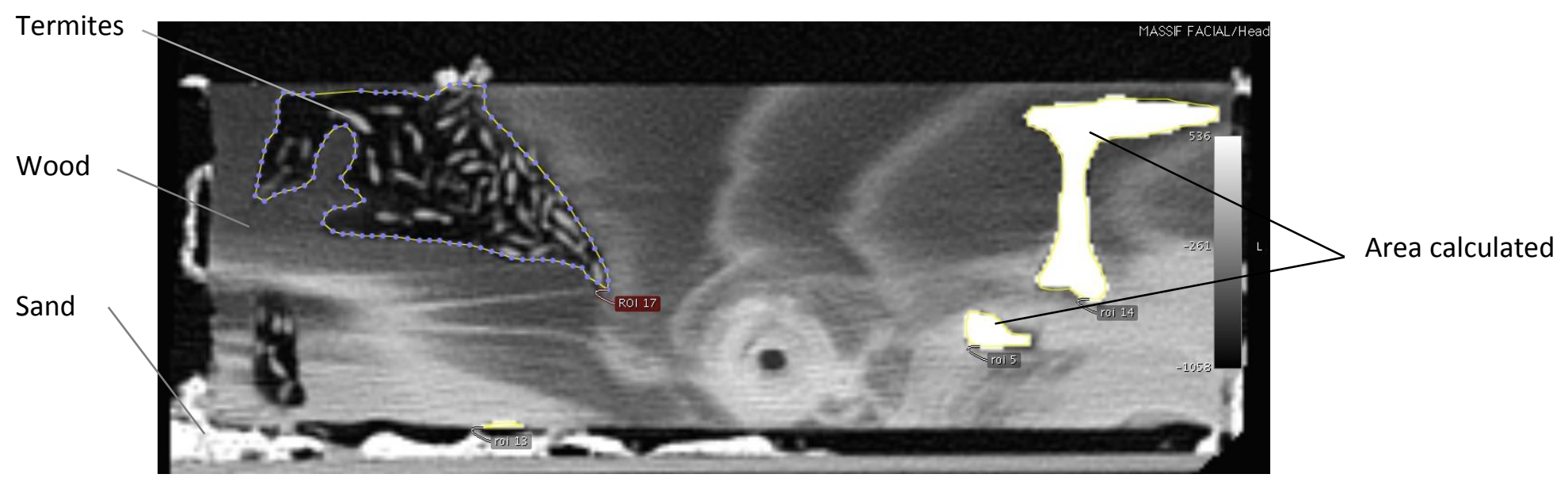


Figure 2.

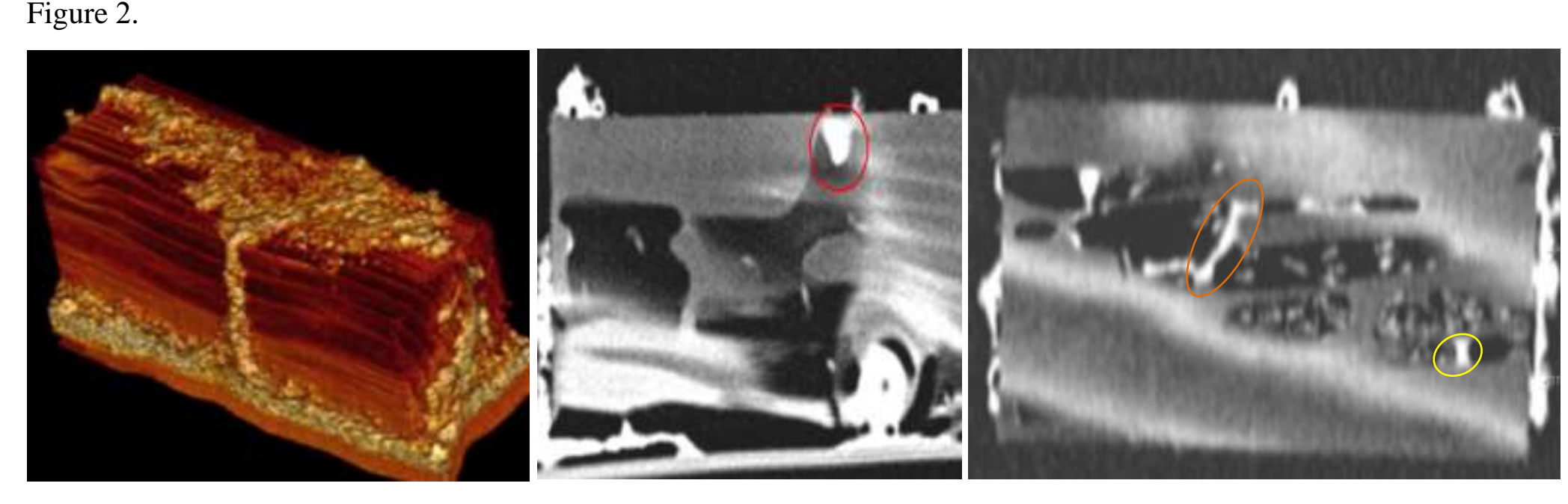




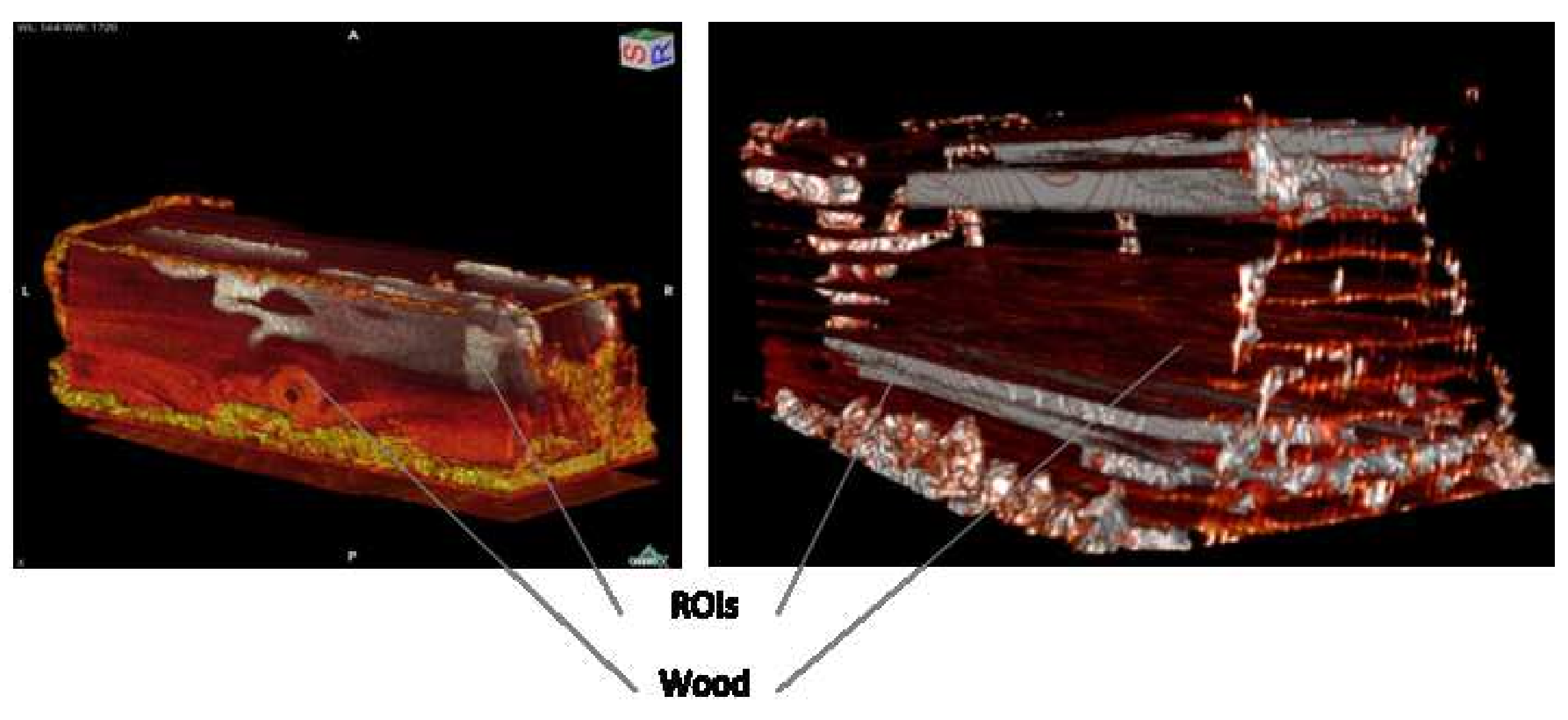




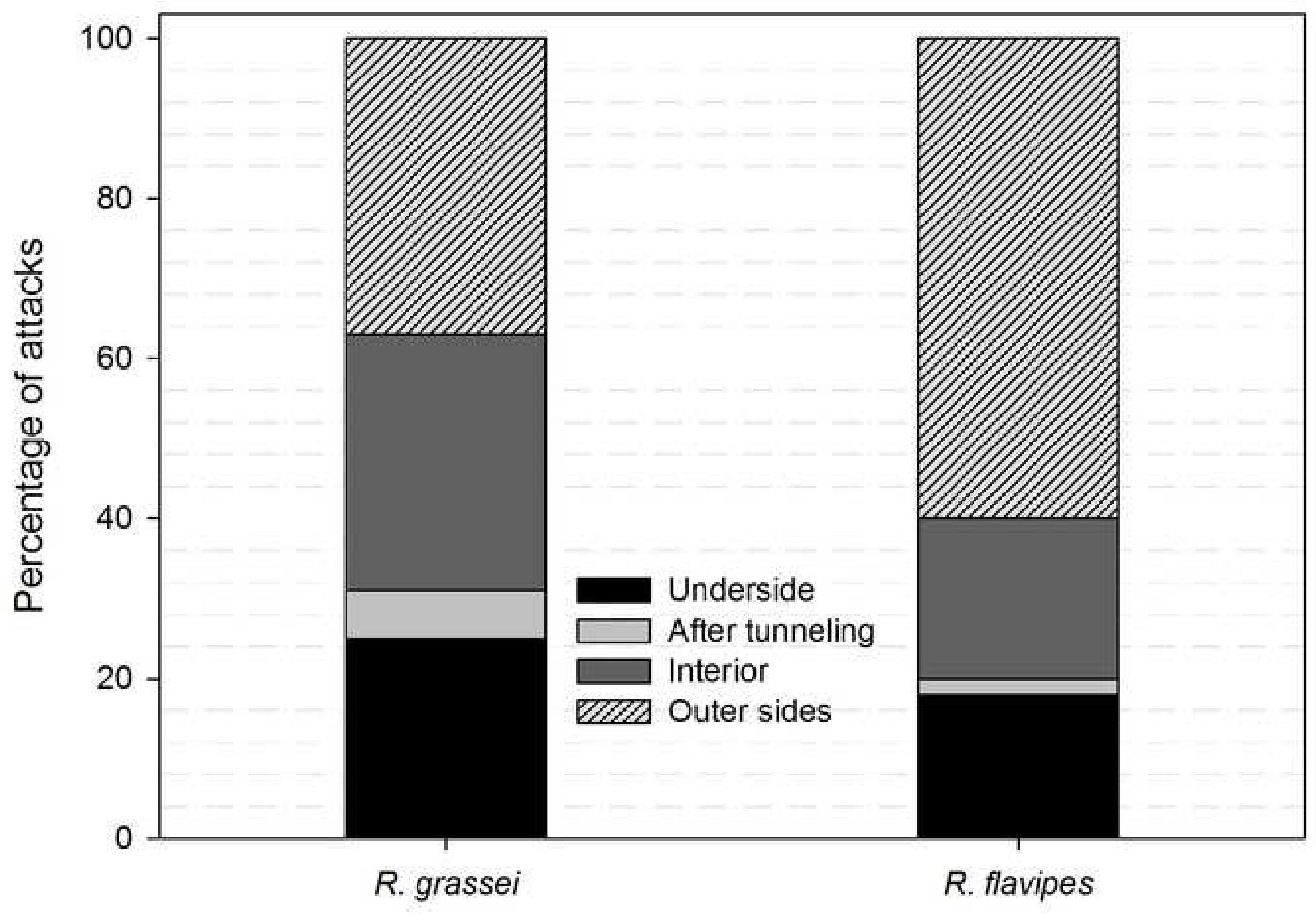



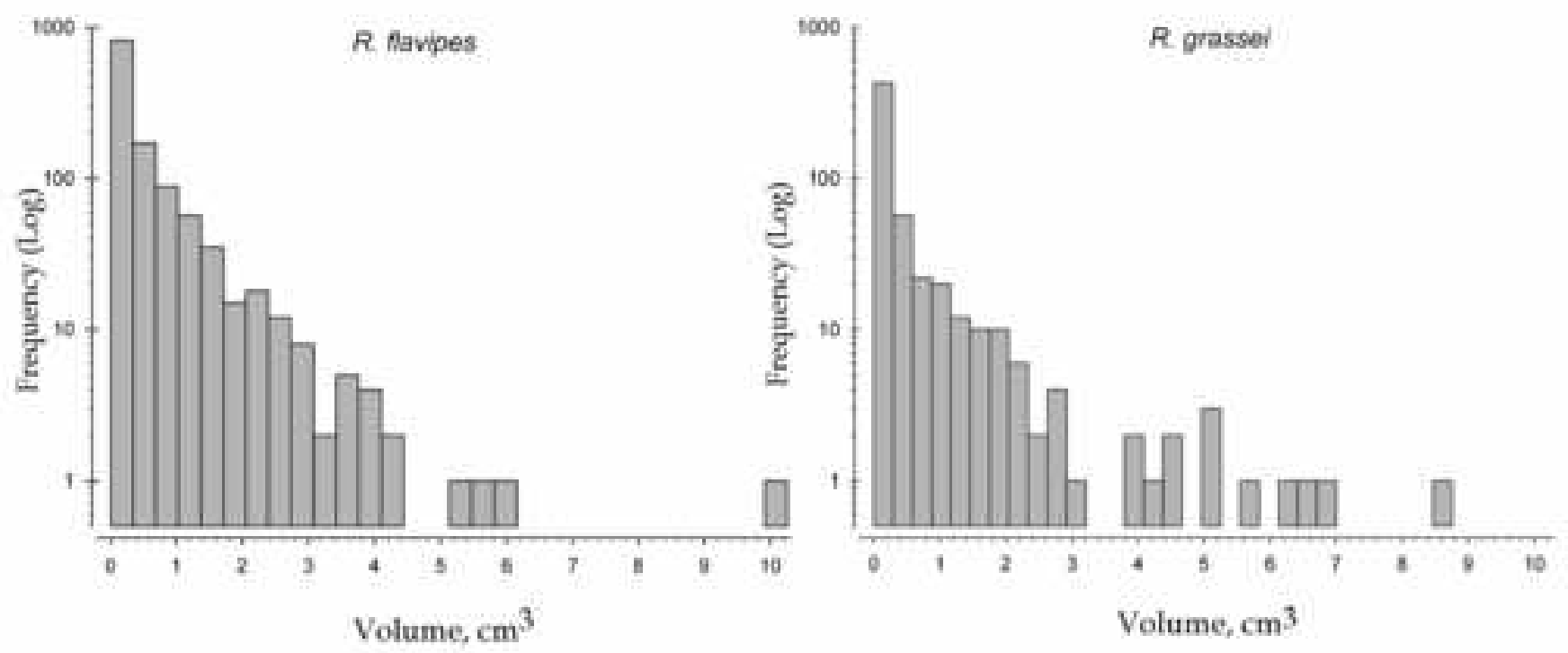


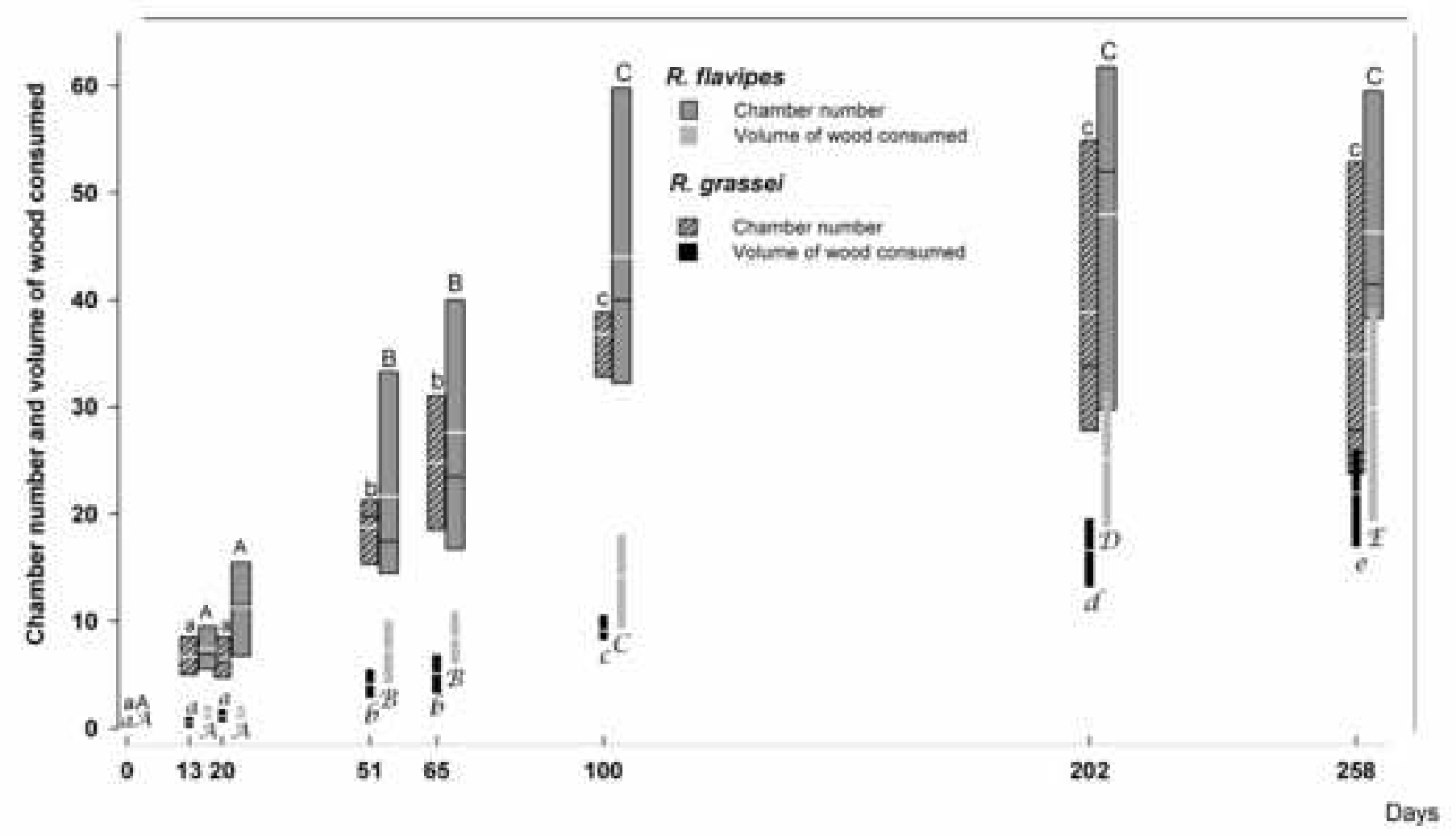




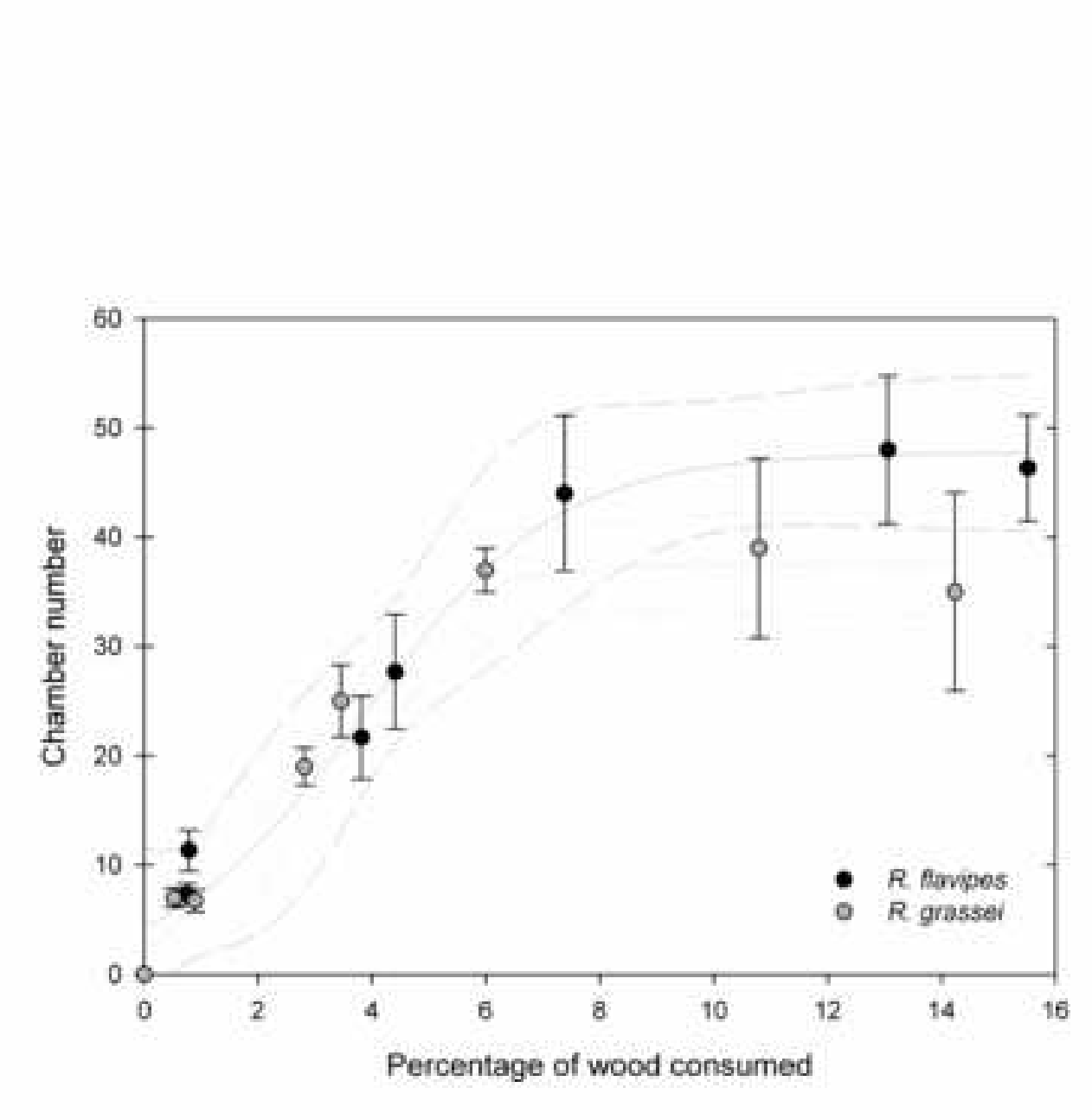

Figure7

Figure7

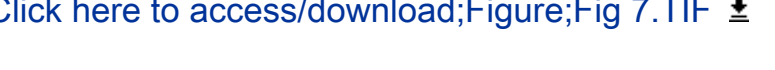

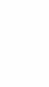

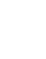

.

(1)

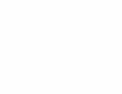

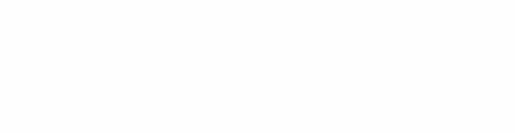

(1)

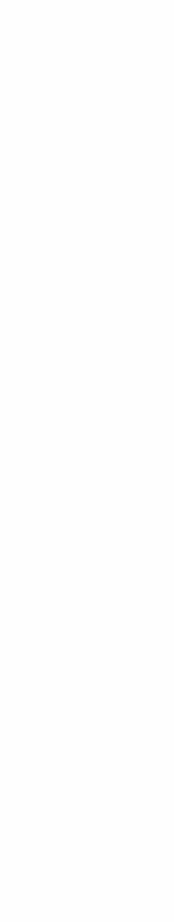




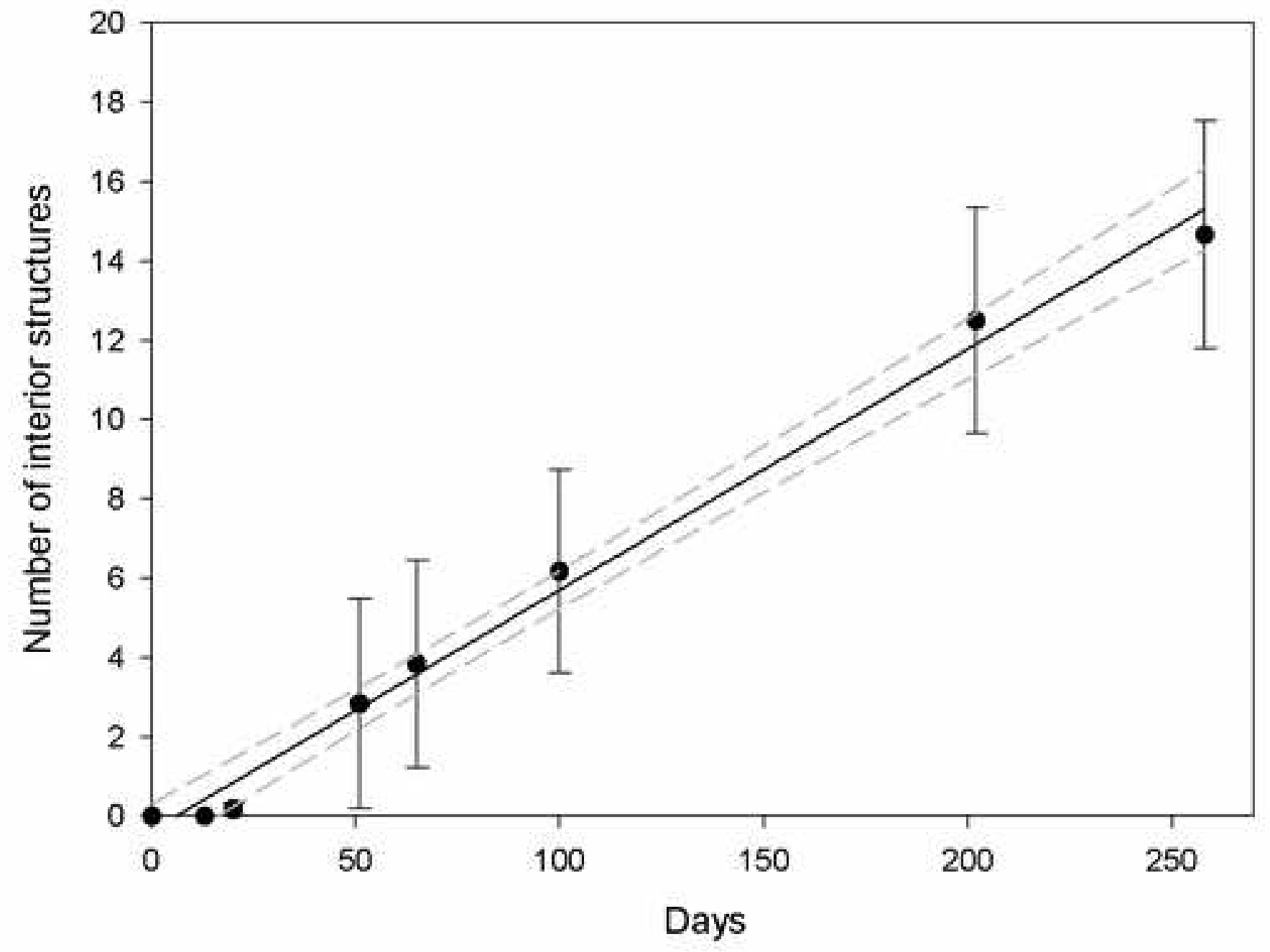




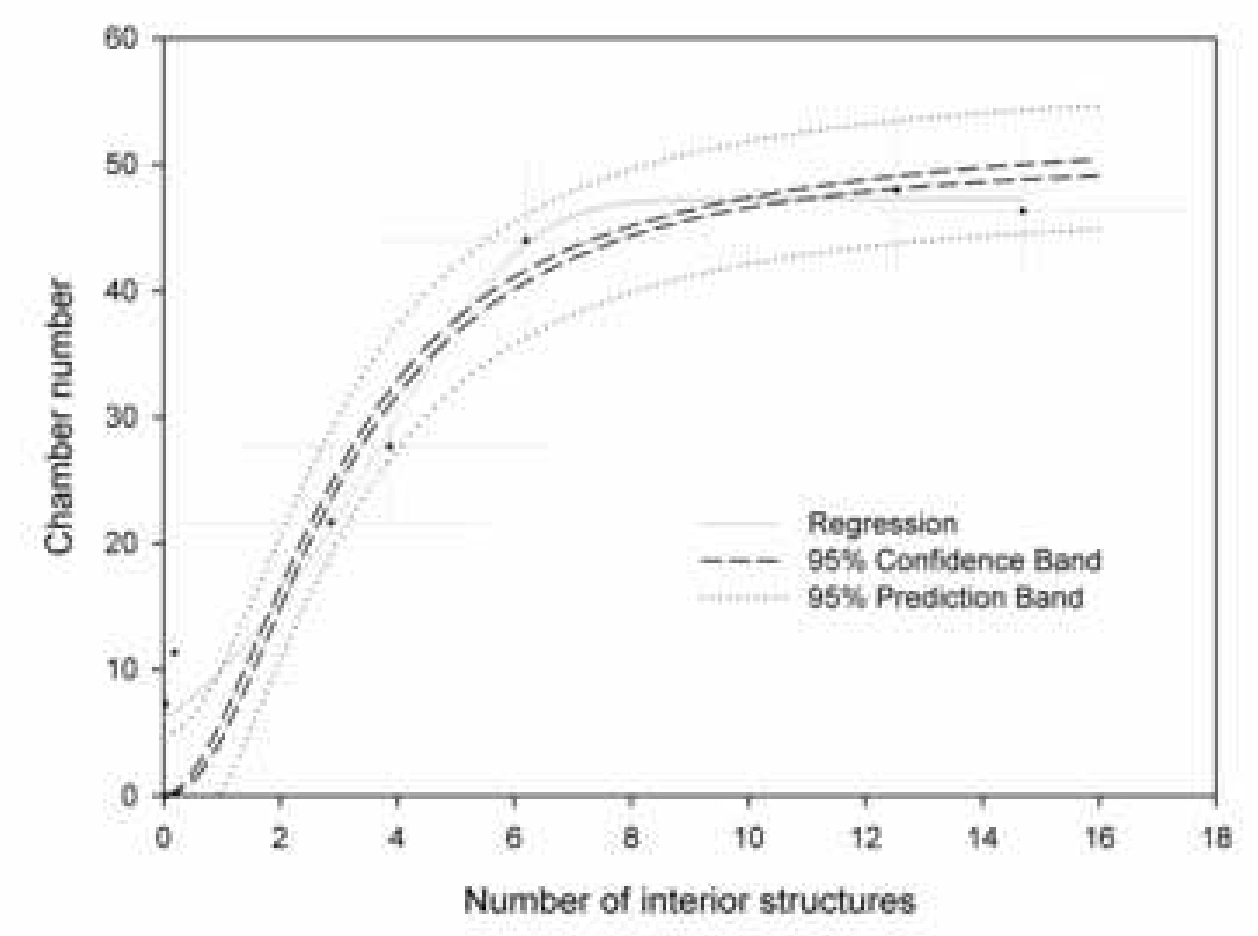

Figure9

(

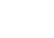

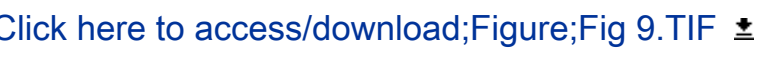

